\title{
Unexpected increase in precipitation intensity with temperature - A result of mixing of precipitation types?
}

\author{
P. Berg a,*, J.O. Haerter ${ }^{b}$ \\ a Institute for Meteorology and Climate Research, KIT, Hermann-von-Helmholtz-Platz 1, Bldg. 435, 76344 Eggenstein-Leopoldshafen, Germany \\ b Max Planck Institute for Meteorology, Bundesstr. 53, 20146 Hamburg, Germany
}

\section{A R T I C L E I N F O}

\section{Article history:}

Received 4 November 2010

Received in revised form 21 May 2011

Accepted 22 May 2011

\section{Keywords:}

Precipitation

Temperature

Convection

Intensity

\begin{abstract}
A B S T R A C T
Using synoptic weather types and comparing high-resolution precipitation and temperature station data, a separation of large-scale and convective precipitation events is performed. We present percentiles of both types and their superposition for varying precipitation accumulation timescales. In some temperature ranges, large-scale, convective and total precipitation percentiles follow increases with temperature at rates higher than that of the saturation humidity increase of the atmosphere of roughly 7\% per degree Kelvin - as given by the Clausius-Clapeyron (CC) relation. However, the increase in total precipitation is found to be due to the transition between the corresponding percentiles of the large-scale and convective types, rather than their individual sections of steep increase. Furthermore, convective precipitation displays a leveling-off towards higher temperatures. This poses further challenges to reconcile arguments brought forward elsewhere - namely those suggesting convective precipitation as the driver of the super-CC increase - with the present observational data.
\end{abstract}

(c) 2011 Elsevier B.V. All rights reserved.

\section{Introduction}

Human life depends both on the availability and manageability of water supplies. Catastrophic societal impacts of precipitation occur on vastly varying timescales: Interannually, lack of rain causes depletion of ground water supplies and reduction or complete loss of crop yields. On seasonal scales, on the one hand, severe water shortage can result - as in the case of the 2003 European heat wave (Fink et al., 2006). On the other, persistent rainfall over several weeks leads to large-scale flooding. On the shortest timescales - from minutes to days - hazards of local flood events such as flash floods (Golding, 2005) range from traffic disruptions and soil erosion to loss of human lives and substantial damage to infrastructure.

Statistical interpretation of rainfall data is challenging due to their irregular temporal behavior, with large variations in intermittancy (Lovejoy and Schertzer, 2006; Peters et al., 2002). Consequently, the statistics of the data depends largely

\footnotetext{
* Corresponding author.

E-mail address: berg@kit.edu (P. Berg).
}

on the temporal resolution at which it is recorded, i.e. the accumulation interval. Exploring the exact functional form of probability density functions (PDFs) of precipitation intensity requires large amounts of reliable observational data, especially when the focus is on extreme events, namely the tail of the distribution function. Generally, PDFs of precipitation intensity peak at low values and fall off rapidly with increasing intensities, but their exact shape again depends on the accumulation interval (Haerter et al., 2010; Wilson and Toumi, 2005).

Temperature fields are more strongly correlated in space and time and their distribution functions are rather symmetric about the mean. However, the consequences of changes in temperature concerning precipitation intensity - especially within the context of global temperature change - are a topic of current discussion in the literature (Allen and Ingram, 2002; Pall et al., 2007; Trenberth et al., 2003). While relative humidity is found to remain roughly constant in simulations of a warming climate, mean precipitation increases at a rate less than that of the atmospheric moisture increase (Held and Soden, 2006). 
On monthly timescales, general correlations between temperature and precipitation have been found globally (Emori and Brown, 2005; Trenberth and Shea, 2005). On shorter timescales of hours and days, Lenderink and van Meijgaard, (2008) (hereafter LM08) explored the relationship of extremes of one hourly resolution precipitation measurements with surface temperature. A scaling following the Clausius-Clapeyron (CC) relationship of approximately $7 \% / \mathrm{K}$ was found for lower temperatures, but above about $12{ }^{\circ} \mathrm{C}$ the scaling changed to a super-CC scaling of approximately $14 \% / \mathrm{K}$. No such change in the scaling was seen for the daily resolution, which was also shown in Berg et al. (2009). LM08 argued for an emergence of super-CC scaling from the statistics due to the dominance of the convective precipitation at shorter timescales, different scaling at higher temperatures than at the lower. In Lenderink and van Meijgaard (2010), the study of LM08 was extended to more stations in the Netherlands, and also in Belgium and Switzerland, with similar results.
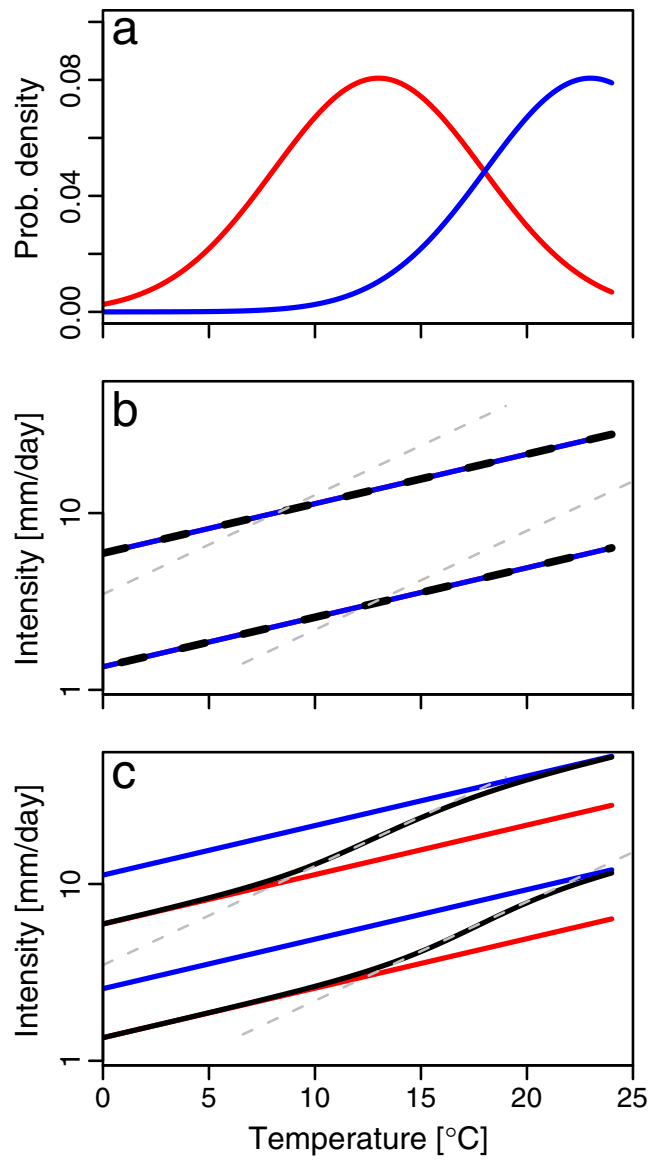

Fig. 1. Reproduction of part of Fig. 1 from Haerter and Berg (2009). (a) Assumed Gaussian distributions of precipitation occurrence for different temperatures for large-scale (red) and convective (blue) precipitation types. (b) Trivial result for the combination of the two types at the daily time scale. Note that the blue and red lines lie on top of each other. (c) The result when changing the time-step from daily to hourly. The dashed gray lines indicate a $2 \times \mathrm{CC}$ rate of change. Note the logarithmic vertical axis in panels b and c.
An interpretation of the results from the LM08 study was brought forward by Haerter and Berg (2009) (hereafter HB09) as summarized in Fig. 1. By assuming a CC rate of change for each of the convective and stratiform precipitation types, it was conceptually shown that a CC rate resulted at the daily timescale where the shorter duration convective precipitation has a relatively small contribution. However, when increasing the resolution to the hourly timescale, the distribution of convective precipitation changes more dramatically than that of stratiform precipitation. At higher temperatures, the contribution of convective precipitation starts to dominate over the stratiform. This means that the individual CC rate of change produces a $2 \times$ CC rate of change for the transition between temperature regimes dominated by each of the single types. The resulting pattern has very similar characteristics to the results shown in LM08. The conceptual study of HB09 was supported with regional climate model results in the supplementary material to the paper.

In the current article we present empirical support for the assumptions put forward in HB09. To this extent we employ 5 -minute resolution data in connection with a data base of synoptic station data in order to separate convective and stratiform precipitation in the time-series. The separated data is then used to test the hypothesis of HB09 of the interplay between the statistics of the two precipitation types in the temporal scaling of extreme precipitation. The data are described in Section 2 and results are presented in Section 3. Discussion and conclusions are given in Section 4.

\section{Data}

At our disposal are 5-minute resolution precipitation data and hourly temperature from the five stations Aachen, Hamburg, Kempten, Saarbrücken, and Schleswig in Germany (Fig. 2 and Table 1). The data were provided by the German Weather Service (DWD), and precipitation was recorded by Hellmann-gauges. While the behavior of total precipitation is similar for all stations (Haerter et al., 2010), the behavior for the two types differs. We therefore separate the stations according to the locations in two groups: ("inland") Aachen, Saarbruecken and Kempten station and ("coastal") Schleswig and Hamburg stations.

The synoptic data originate from the Extended Edited Synoptic Cloud Report Archive (EECRA) data base (Hahn and Warren, 1999), and each of the precipitation stations listed above has a matching synoptic station in this data set. We classify the precipitation measurements according to the cloud types as convective when there are convective clouds $(C L=1$, $2)$, cumulonimbus $(\mathrm{CL}=3,9)$ or the extra class of the EECRA data set for thunder $(C L=10)$. Precipitation is treated as stratiform when there are stratus $(\mathrm{CL}=6,7)$ or nimbostratus $(\mathrm{CM}=2,7,10,11,12)$ clouds, according to the classes presented in Hahn and Warren (1999). The classification is very strict in the sense that no mixing of the two classes is allowed. This means that the convective precipitation discussed in this paper is not associated with frontal stratiform systems. This is a necessary restriction in order to associate a time interval with a certain precipitation type. A brightness indicator is used as a reliability indicator on the observation, i.e. only observations in conditions with sufficiently bright conditions are considered reliable. In this study we use only data that fulfill the brightness criteria of the data set. Due to the different time 


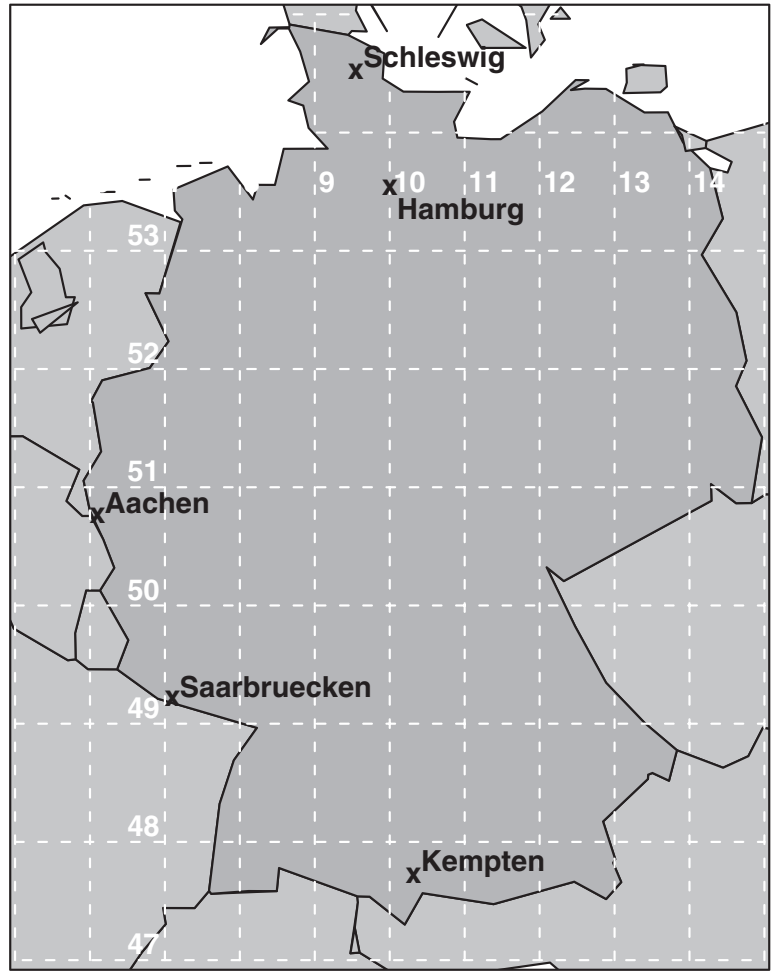

Fig. 2. Locations of the stations within Germany. The numbers indicate degree latitude and longitude.

periods of the synoptic and precipitation data, we are confined to the observational periods shown in Table 1. As the synoptic data are only available at a three hourly resolution, we assume that the observations are valid for $1.5 \mathrm{~h}$ before and after the time of the observation as the atmospheric state does not change significantly within this time-period. Shorter time periods surrounding the observations were also investigated with no significant changes to the results (not shown), however some extent of mixing between types cannot be ruled out. A second approach of using weather reports, from the same data base, to classify precipitation was also tested and gave similar results.

The relationship between precipitation and temperature was investigated by breaking down the precipitation timeseries according to the associated temperature, i.e. precipitation measurements were placed into temperature-conditional bins and distribution functions were then derived for each bin separately. We use temperature bins of $5 \mathrm{~K}$ and perform the calculations in steps of $3 \mathrm{~K}$, i.e. with some overlap, in order to

Table 1

Stations and overlapping data periods for precipitation and temperature measurements and synoptic classification.

\begin{tabular}{lll}
\hline Station name & Latitude; Longitude & Record period (month/day/year) \\
\hline Aachen & $50^{\circ} 47^{\prime} \mathrm{N} ; 6^{\circ} 06^{\prime} \mathrm{E}$ & $01 / 01 / 1971-12 / 13 / 1981$ \\
Hamburg & $53^{\circ} 38^{\prime} \mathrm{N} ; 9^{\circ} 59^{\prime} \mathrm{E}$ & $01 / 01 / 1971-12 / 31 / 1984$ \\
Kempten & $47^{\circ} 43^{\prime} \mathrm{N} ; 10^{\circ} 20^{\prime} \mathrm{E}$ & $01 / 01 / 1971-12 / 31 / 1987$ \\
Saarbrücken & $49^{\circ} 13^{\prime} \mathrm{N} ; 7^{\circ} 07^{\prime} \mathrm{E}$ & $01 / 01 / 1971-11 / 30 / 1976$ \\
Schleswig & $54^{\circ} 32^{\prime} \mathrm{N} ; 9^{\circ} 33^{\prime} \mathrm{E}$ & $01 / 01 / 1971-12 / 31 / 1980$ \\
\hline
\end{tabular}

get good statistics in each bin. Only precipitation intervals with more than $0.1 \mathrm{~mm}$ were used, based on the measurement accuracy of the data. The hourly temperature data were interpolated to the 5-minute resolution. This has no large effect on the results, as our temperature bins are generally larger than the fluctuation of temperature within $1 \mathrm{~h}$. A lower limit of 300 data points was used for each bin. Similar results are achieved when using the constant hourly temperature associated with each 5-minute interval (not shown).

\section{Results}

The diurnal frequency cycle for all wet days in the gauge data is shown in Fig. 3a for the coastal group and Fig. 3b for the inland group. There is very limited convective activity in this region during the winter months (DJF, dotted), and the diurnal cycle with an early morning peak is therefore associated to the large-scale precipitation type. This is supported by the annual cycle of synoptic observations shown in Fig. 3d. Note that the morning peak structure is similar for both groups of stations. In summer (JJA, dashed), convection plays a larger role in determining the diurnal cycle, however the shape differs for the two groups of stations. The coastal stations have a peak near the end of the day, perhaps due to influence of the sea, while the peak for the inland stations occurs in the late afternoon.

Fig. $3 c$ and $d$ shows the number of synoptic observations over the day for the inland stations (the structure for the coastal stations is similar). Comparing the frequency of precipitation for summer in Fig. 3b to the observations of convective cloud types in Fig. 3c, there is a clear correlation between convective cloud observations and the summertime diurnal precipitation frequency cycle. The impact of brightness problems during night can be expected to be larger for the convective precipitation for the coastal stations than for the inland stations due to the late evening peak (Fig. 3a). The bias in the observations for the large-scale precipitation is obvious as the cloud observations have a clear day-night diurnal cycle, which does not fit at all with the precipitation observations (Fig. 3b). Strong systematic differences between night-time and daytime intensities might affect the results of this study, however as the majority of the precipitation events occur in conditions with fulfilled brightness criteria the impact can be expected to be minor.

Fig. 4a shows the normalized probability density function of the occurrence of 5-minute precipitation intervals for each temperature bin for the inland stations. The distributions found here are close to those assumed in HB09 (see Fig. 1a), with distributions similar to Gaussians centred at 7 and $15^{\circ} \mathrm{C}$, even though the weighting between the different types is different due to the dominance of the stratiform precipitation. The difference in the weighting is evident when studying the distribution of total precipitation (black curve) as this follows the stratiform precipitation to a larger degree. For the coastal stations, the convective type might not be well separated from the large-scale type, as a consequence of the day-night bias in connection with the concentration of the events to the late evening for this group (not shown). Furthermore, there is not as clear a convection peak for the coastal stations as the typical weather situation is more of frontal type and the formation of convection is not as clearly separated as for the inland stations. We therefore focus the analysis on the inland 

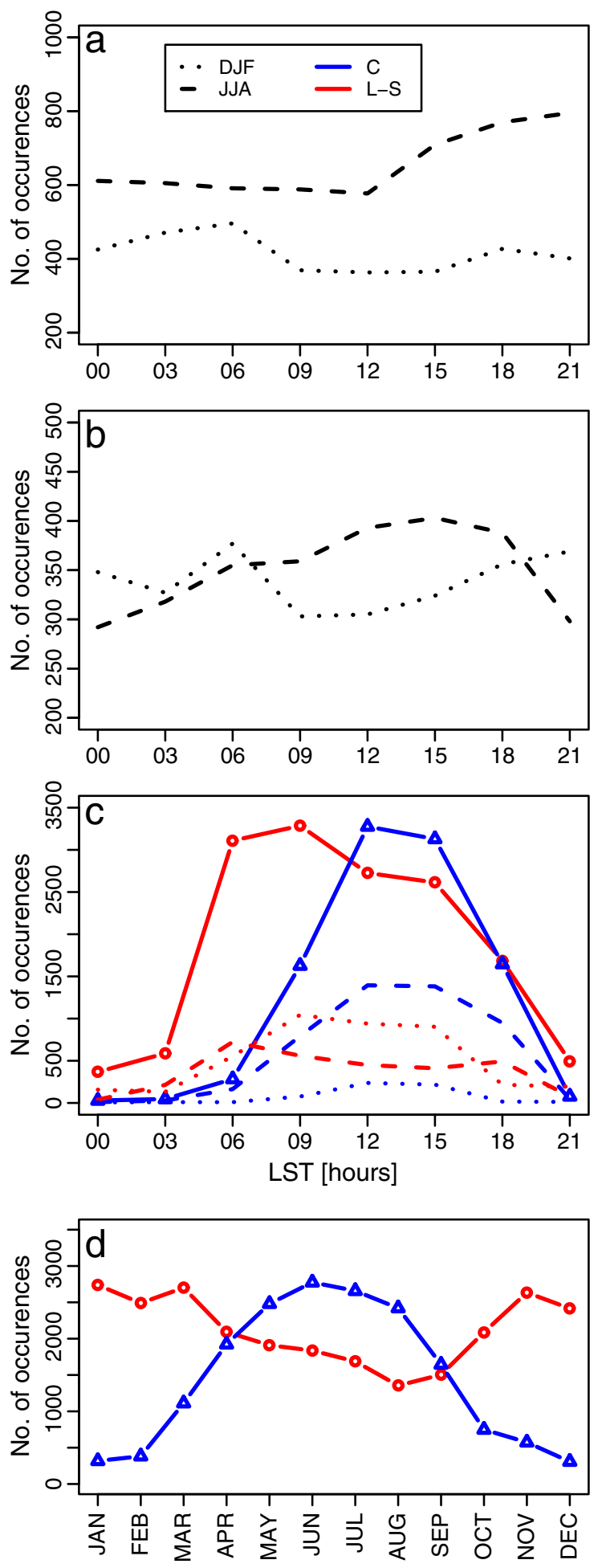

Fig. 3. Diurnal cycle of occurrences of precipitation in winter (dotted) and summer (dashed) for all recorded intervals of the coastal (a) and inland (b) groups. (c) The number of synoptic observations of convective (blue triangles) and stratiform (red circles) cloud types for all year (solid), winter (dotted) and summer (dashed). (d) The annual cycle of synoptic observations of the two types. stations, even though the results are similar but less clear for the coastal stations.

The distribution functions for the exceedence probability of precipitation intensities are shown in Fig. 4b. The distributions of the two types change in shape, and relative to each other when decreasing the temporal resolution from 5-minutes (solid) to $1 \mathrm{~h}$ (dashed). At the 5-minute resolution the intensity of convective events is much larger down to the lowest exceedence probabilities. The likelihood of exceeding $10 \mathrm{~mm} / 5 \mathrm{~min}$ is one hundred times larger for convective precipitation. At the hourly resolution there is a crossover of the two curves at about $5 \mathrm{~mm} / \mathrm{h}$. While it is more likely to find large-scale events that exceed an intensity of $1 \mathrm{~mm} / \mathrm{h}$, events of more than $3 \mathrm{~mm} / \mathrm{h}$ are increasingly more likely to be of the convective type. Typical contiguous large-scale and convective events have durations of less than $1 \mathrm{~h}$. Hence, when taking hourly measurements, dry periods are mixed in with precipitating periods. However, large-scale events on average last longer than convective events. The dominance of large-scale precipitation at the lower intensities is hence due to the longer duration of large-scale events. At the higher intensities, the discrepancy of the solid curves in Fig. 4b dominates even the hourly statistics, hence leading to the crossover as seen in the dashed curves near $3 \mathrm{~mm} / \mathrm{h}$.

LM08 showed that increases in precipitation intensity with temperature are not constrained by the $\mathrm{CC}$ rate when sufficiently short - in their case hourly - accumulation intervals were chosen. In Haerter et al. (2010), the LM08 study was extended by using data of even higher temporal resolution ( $5 \mathrm{~min}$ ) and presenting explicitly the changes of the PDFs with timescales. However, in both of these studies no explicit separation between the large-scale and the convective type was made. Hence, interpretations of super-CC increases remained largely speculative.

Therefore, we now show the dependence of precipitation intensity on temperature for the two types separately (Fig. 4c and d). We first focus on the 99th percentile of wet intervals $(>0.1 \mathrm{~mm})$, hence rather extreme precipitation. The statistics of total precipitation, i.e. the sum of large-scale and convective types (black curves) does show a clear super-CC increase for the 5-minute data and to a weaker extent also for the hourly data. Due to the shift of the occurrence probability (Fig. 4a, gray curve) total precipitation follows the temperature dependence of the stratiform type at lower temperatures and closer to that of convective precipitation at the higher temperatures. When the two precipitation types are distinguished, we find that there are intervals where both large-scale and convective precipitation increase at a rate higher than the CC rate. This is especially pronounced for the 5-minute data. However, the super-CC increase in total precipitation (black curve in Fig. 4c) is due to a transition between the curves of large-scale (low temperatures) and convective types (high temperatures) which is commensurate with the arguments made in HB09. For the 75th percentile the increase does not exceed the CC rate for either precipitation type individually, however, in the case of the 5-minute data in the transition range between the large-scale and convective curve between 15 and $20^{\circ} \mathrm{C}$ a steeper increase of the joint percentile (black curve) results. Note the onset temperatures of the super-CC increases: For the 99th percentile, the steep rise begins near $10^{\circ} \mathrm{C}$ while for the 75 th percentile, it occurs near $15^{\circ} \mathrm{C}$. This is very much in-line with 

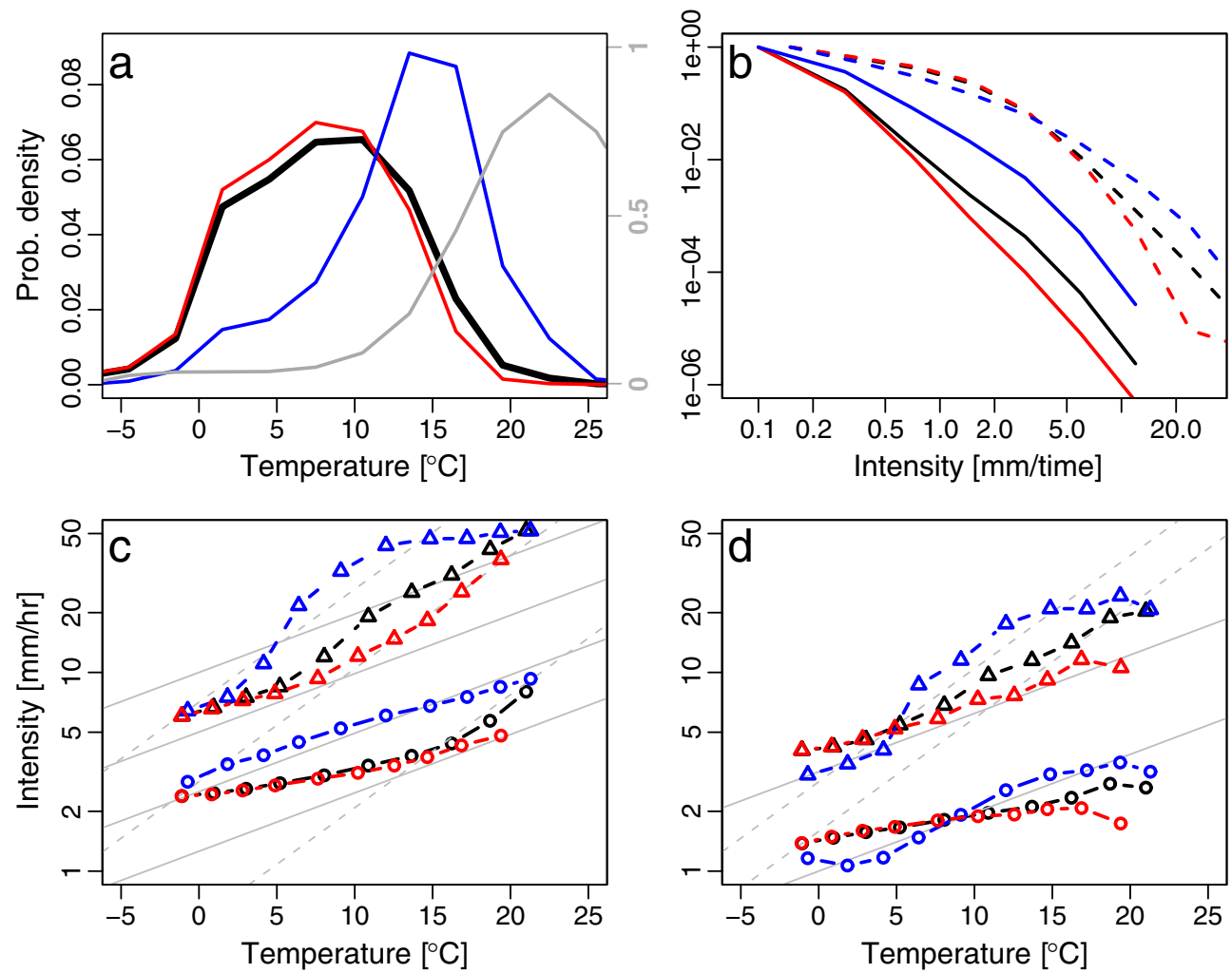

Fig. 4. Results for inland stations: (a) two meter temperature distributions for stratiform (red), convective (blue) and total (black) precipitation events. The relative contribution of convective events to the total number of events is shown in gray. (b) distributions of the different precipitation types for 5-minute (solid) and hourly resolution (dashed). (c) the relationship between temperature and the 75th (circles) and 99th (triangles) percentiles for 5-minute temporal resolution. (d) same as (c), but for hourly resolution.

the findings from LM08 (see their Fig. 1a) where similar behavior was found.

It is also important to realize that the curve of convective precipitation intensity (both in Fig. 4c and d) increases rapidly between 5 and $10{ }^{\circ} \mathrm{C}$ but displays rather featureless temperature dependence at higher temperatures. Conversely, the curve of total precipitation does not show any sign of saturation up to the highest temperatures, as was also pointed out in LM08. The separation hence allows speculations on possible behavior in a warming climate: If more data at higher temperatures $\left(>20^{\circ} \mathrm{C}\right)$ would become available, the curve of total precipitation could be found to flatten out in that range, following the blue curve in the figure. This would lead to a sub-CC increase at those temperatures, which were difficult to obtain from the LM08 study.

\section{Summary and conclusions}

We have used synoptic codes to separate stratiform and convective precipitation data. By matching with high-resolution temperature and rain gauge station data of 5-minute accumulation intervals, statistics as function of surface temperature and percentile were obtained. Our analysis demonstrates that a super-CC increase of precipitation intensity percentiles with temperature occurs in the transition-temperature region where the stratiform (low temperatures) and convective precipitation (high temperatures) types are of similar frequency. Our results are in-line with an earlier hypothesis brought forward in HB09 where such a statistical effect was discussed. Furthermore, we find here that increases beyond the $\mathrm{CC}$ rate are possible for each precipitation type independently, however at rather lower temperatures than mentioned in LM08. We point out that the separation of the types actually reveals a saturation of the curve of convective precipitation towards the higher temperatures and only in the mixing of the two types does a seemingly unsaturated increase occur.

In conclusion, we believe that the finding presented here should trigger deeper investigations into the origin of the disparate behavior of the two precipitation types. One path to take in its exploration could be to conduct convection resolving model simulations for an isolated test region with changing surface and lateral boundary conditions.

\section{Acknowledgements}

We acknowledge partial financial support by the German project CEDIM and the EU-project WATCH (contract number 036946). Furthermore, we acknowledge the use of the station data from the German Weather Service (DWD) and the synoptic station data from the EECRA data base. 


\section{References}

Allen, M.R., Ingram, W.J., 2002. Constraints on future changes in climate and the hydrologic cycle. Nature 419, 224-232.

Berg, P., Haerter, J.O., Thejll, P., Piani, C., Hagemann, S., Christensen, J.H., 2009. Seasonal characteristics of the relationship between daily precipitation intensity and surface temperature. J. Geophys. Res. 114, D18102. doi:10.1029/2009JD012008.

Emori, S., Brown, S.J., 2005. Dynamic and thermodynamic changes in mean and extreme precipitation under climate change. Geophys. Res. Lett. 32, L17706. doi:10.1029/2005GL023272.

Fink, A.H., Bruecher, T., Krueger, A., Leckebusch, G.C., Pinto, J.G., Ulbrich, U., 2006. The 2003 European summer heatwaves and drought - synoptic diagnosis and impacts. Weather 59, 209-216.

Golding, B.W., 2005. Boscastle and north Cornwall post flood event studymeteorological analysis of the conditions leading to flooding on 16 August 2004. Technical Report 459. Met Office, Devon, UK.

Haerter, J.O., Berg, P., 2009. Unexpected rise in extreme precipitation caused by a shift in rain type? Nat. Geosci. 2.

Haerter, J.O., Berg, P., Hagemann, S., 2010. Heavy rain intensity distributions on varying time scales and at different temperatures. J. Geophys. Res. 115, D17102. doi:10.1029/2009JD013384.
Hahn, C., Warren, S., 1999. Extended edited synoptic cloud reports from ships and land stations over the globe. Technical Report. Department of Energy, Oak Ridge, Tennessee.

Held, I., Soden, B.J., 2006. Robust responses of the hydrological cycle to global warming. J. Climate 19, 5686-5699.

Lenderink, G., van Meijgaard, E., 2008. Increase in hourly precipitation extremes beyond expectations from temperature changes. Nat. Geosci. 1, 511-514.

Lenderink, G., van Meijgaard, E., 2010. Linking increases in hourly precipitation extremes to atmospheric temperature and moisture changes. Environ. Res. Lett. 5, 025208. doi:10.1088/1748-9326/5/2/025208.

Lovejoy, S., Schertzer, D., 2006. Multifractals, cloud radiances and rain. J. Hydrol. 322, 59-88.

Pall, P., Allen, M.R., Stone, D.A., 2007. Testing the Clausius-Clapeyron constraint on changes in extreme precipitation under $\mathrm{CO}_{2}$ warming. Clim. Dyn. 28, 351-363.

Peters, O., Hertlein, C., Christensen, K., 2002. A complexity view of rainfall. Phys. Rev. Lett. 88, 018701. doi:10.1103/PhysRevLett.88.018701.

Trenberth, K.E., Shea, D.J., 2005. Relationships between precipitation and surface temperature. Geophys. Res. Lett. 32, L14703. doi:10.1029/2005GL022760.

Trenberth, K.E., Dai, A., Rasmussen, R.M., Parsons, D.B., 2003. The changing character of precipitation. Bull. Am. Meteor. Soc. 84, 1205-1217.

Wilson, P.S., Toumi, R., 2005. A fundamental probability distribution for heavy rainfall. Geophys. Res. Lett. 32, L14812. doi:10.1029/2005GL022465. 